\title{
Transfer Factors: Identification of Conserved Sequences in Transfer Factor Molecules
}

\author{
Charles H. Kirkpatrick \\ Department of Medicine, Division of Allergy and Immunology, University of \\ Colorado Health Sciences Center, Denver, Colorado, U.S.A.
}

Accepted February 10, 2000

\begin{abstract}
Background: Transfer factors are small proteins that "transfer" the ability to express cell-mediated immunity from immune donors to non-immune recipients. We developed a process for purifying specific transfer factors to apparent homogeneity. This allowed us to separate individual transfer factors from mixtures containing several transfer factors and to demonstrate the antigen-specificity of transfer factors. Transfer factors have been shown to be an effective means for correction of deficient cellular immunity in patients with opportunistic infections, such as candidiasis or recurrent Herpes simplex and to provide prophylactic immunity against varicellazoster in patients with acute leukemia.

Materials and Methods: Transfer factors of bovine and murine origin were purified by affinity chromatography and high performance liquid chromatography. Cyanogen bromide digests were sequenced. The properties of an apparently conserved
\end{abstract}

sequence on expression of delayed-type hypersensitivity by transfer factor recipients were assessed.

Results: A novel amino acid sequence, LLYAQDL/VEDN, was identified in each of seven transfer factor preparations. These peptides would not transfer expression of delayed-type hypersensitivity to recipients, which indicates that they are not sufficient for expression of the specificity or immunological properties of native transfer factors. However, administration of the peptides to recipients of native transfer factors blocked expression of delayed-type hypersensitivity by the recipients. The peptides were not immunosuppressive.

Conclusions: These findings suggest that the peptides may represent the portion of transfer factors that binds to the "target cells" for transfer factors. Identification of these cells will be helpful in defining the mechanisms of action of transfer factors.

\section{Introduction}

Transfer factors are products of $\mathrm{T}$ lymphocytes that transfer the ability to express delayed-type hypersensitivity and cell-mediated immunity from sensitized donors to non-immune recipients (1). A significant body of evidence indicates that this activity is antigen-specific (2-5). To date, neither the primary structures nor the mechanisms of action of transfer factors have been defined. However, recent studies have shown that transfer factors can be purified to a high degree of homogeneity and that the purified transfer factors are proteinaceous and immunologically specific (6). As part of a program

Address correspondence and reprint requests to: Charles H. Kirkpatrick, 1899 Gaylord Street, Denver, CO 802061210, U.S.A. Phone: 303-333-9625. Fax: 303-333-9621. that is directed at determining the primary structures of transfer factors, we isolated and sequenced two closely related peptides that appeared to be conserved regions of transfer factor molecules. These peptides were isolated from transfer factors of different specificities and from both murine and bovine transfer factor donors.

Administration of synthetic peptides with the same sequence to murine recipients did not transfer the ability to express cell-mediated immunity. Thus, the peptides were not sufficient for the immunologic activity or specificity of transfer factors. However, administration of the same synthetic peptides "blocked" the immunological activity of transfer factors in transfer factor-treated recipients. This may indicate that the peptides occupy binding sites on the "target cells" for transfer factors. 


\section{Materials and Methods}

\section{Mice}

All experiments were done with (BALB/cByJ) female mice, aged 10-16 weeks (The Jackson Laboratory, Bar Harbor, ME). They were housed in a Thorens Maxi-Miser Caging System (Thorens Caging Systems, Inc., Hazelton, PA) and given food and water ad libitum. The protocols for these studies were approved by the Animal Care and Use Committee of Cytokine Sciences Inc, Denver, Co).

\section{Antigens and Immunizations}

Ovalbumin was purchased from Sigma Chemical Co. (St. Louis, MO). Horse spleen ferritin was purchased from ICN Immunobiologicals (Lisle, IL). Human Herpes simplex virus, type 1 (HSV-1) was a gift from Dr. Adriana Weinberg, University of Colorado Health Sciences Center (Denver, CO). The virus was propagated in human embryonic lung fibroblasts, which were then lysed by ultrasound. The virus was partially purified by ultracentrifugation. The final preparation produced $2 \times 10^{8}$ lytic plaques $/ \mathrm{ml}$ on confluent fields of human embryonic fibroblasts. For use as an antigen, suspensions of virulent HSV were exposed to ultraviolet light $\left(2200 \mu\right.$ watts $/ \mathrm{cm}^{2}$; distance $7.6 \mathrm{~cm}$ ) for $30 \mathrm{~min}$ at $4^{\circ} \mathrm{C}$. Recombinant HSV-1 glycoprotein D (HSV-gD) was provided by Drs. Gary Cohen and Roselyn Eisenberg of the University of Pennsylvania School of Dentistry, Philadelphia, PA (7). This protein was truncated at 306 amino acids from the aminoterminus and had 6 histidine molecules at the carboxy-terminus.

For use as antigens, the proteins were diluted in Hanks' Balanced Salt Solution (HBSS) to $5 \mathrm{mg} / \mathrm{ml}$ and emulsified into equal volumes of Freund's complete adjuvant (FCA) (Sigma). Mice were immunized by injection of $20 \mu \mathrm{l}$ into each of two sites at the base of the tail. Cattle were immunized with undiluted irradiated HSV-1 that was emulsified into an equal volume of FCA. $2 \mathrm{ml}$ of the emulsion were divided into multiple subcutaneous sites $(0.2 \mathrm{ml} /$ site) along the flank.

\section{Testing for Delayed-type Hypersensitivity}

UV-irradiated HSV-1 (initial concentration $10^{8} \mathrm{pfu} / \mathrm{ml}$ ) was used as the test antigen. For testing bovine calves, $0.1 \mathrm{ml}$ was injected intradermally in the lateral neck. A diluent con- trol was also injected. Induration responses were measured at 48 and $72 \mathrm{hr}$; indurations of greater than $0.5 \mathrm{~cm}$ were scored as positive. The usual responses to HSV were 2.0 to $2.5 \mathrm{~cm}$; There were no responses to diluent.

The footpad swelling response was used for mice (3). The reagents and mice were coded so that the reader did not know the treatments given to the groups of mice. The assay for transfer factor activity was done $24 \mathrm{hr}$ after intraperitoneal administration of the transfer factor to the mice. The same HSV-1 antigen used for bovine experiments was used for the mice. For ovalbumin (OVA) and ferritin, the antigen concentration was $4 \mathrm{mg} / \mathrm{ml}$ in HBSS. After the footpads were measured with a micrometer caliper (Starrett Tools, Athol, MA), $25 \mu \mathrm{l}$ of antigen solution were injected into one footpad; $25 \mu \mathrm{l}$ of HBSS were injected into the contralateral footpad. The changes in footpad thickness were measured $18 \mathrm{hr}$ later. There were six mice in each test group. Replicate measurements varied by approximately $2-4 \%$. The mean changes were analyzed with Student's $t$-test.

Preparation of Transfer Factor Containing Dialysates

BALB/cByJ mice were sensitized as described above. After 3-4 weeks, six mice were randomly selected and tested for expression of delayed-type hypersensitivity (DTH) with the footpad swelling assay. If the result was positive, the remaining mice were euthanized with carbon dioxide, their spleens were removed and single cell suspensions were prepared.

Bovine calves were bled from the jugular vein into bottles containing sterile $3.2 \%$ sodium citrate solution. The whole blood was washed with HBSS to remove plasma proteins. The leukocytes were counted and processed as described below. Eventually, the calves were euthanized and the spleens were collected. The cellular content of the whole spleen was estimated from the cell count and differential count of a 2-3 gram sample of the spleen. Single-cell suspensions were prepared for lysis and dialysis as described (6).

The cells were counted, then lysed by freezing and thawing, and the lysate was dialyzed through Spectra/por 1 membranes (Spectrum Medical Industries, Inc., Los Angeles, CA) that had been boiled and had a nominal cut off of 6,000 Da. Transfer factors will pass through these membranes (6). The dialysate 
was concentrated by tangential flow ultrafiltration (Millipore Corp., Milford, MA) with a 1000 Da cutoff membrane or by lyophilization. An aliquot was reserved for assay of transfer factor activity by the footpad swelling assay.

\section{Purification of Transfer Factors}

Transfer factors bind to antigen in an antigenspecific manner $(5,8)$. OVA-specific and ferritin-specific transfer factors were purified on antigen-coated Immulon-2 microtiter wells (Dynatech Laboratories, Alexandria, VA) as described previously $(6,8)$. HSV- 1 specific transfer factor of murine or bovine origin was purified on recombinant HSV-1 glycoprotein D (gD) that had the six amino acids at the carboxy-terminus replaced by six histidine molecules (7). The glycoprotein D (305t-6 His) was covalently bound to nickel-NTA-agarose beads (Qiagen, Inc., Chatsworth, CA) for use as a solid phase absorbent.

After incubation on antigen, the wells or beads were washed and the transfer factors were eluted with acetonitrile and 50:50 mixtures of acetonitrile:water. The acetonitrile was removed by evaporation with nitrogen at $37^{\circ} \mathrm{C}$; water was removed by lyophilization. An aliquot of the eluate was reserved for assay for transfer activity.

The next step involved high performance liquid chromatography (HPLC) on octadecyl silane (Vydac 218 TP 54, Hesperia, CA) using $5 \mathrm{mM}$ ammonium bicarbonate and a gradient of acetonitrile (6). (We have found that trifluoracetic acid irreversibly denatures transfer factors.) Approximately $25 \times 10^{8}$ lymphocyte equivalents of transfer factor-containing material was dissolved in $1.0 \mathrm{ml}$ of Milli-Q water, then filtered through a $0.2 \mu \mathrm{m}$ Millex filter (Millipore) and applied to the C18 column. Elution was monitored at $214 \mathrm{~nm}$; the flow rate was $1 \mathrm{ml} / \mathrm{min}$. Each peak that absorbed at $214 \mathrm{~nm}$ was assayed for transfer factor activity with the footpad swelling assay. The active peaks from 5 separate runs were pooled, dialyzed with a Spectra/por 7 membrane (Molecular Weight Cut Off [MWCO]-1000 Da) and lyophilized. The products of this purification gave single peaks with HPLC with two different solvent systems, a single peak on Sephadex G-10 exclusion chromatography and a single band on SDS-PAGE (6).

\section{Cleavage with Cyanogen Bromide}

Several attempts at sequencing the intact purified molecules were not successful. It was assumed that the amino terminus of the molecules was blocked, but the nature of the blocking moiety was not identified.

After confirming that the product had transfer factor activity by the footpad assay, samples were dissolved in Milli-Q water and concentrated on polyvinyl difluoride membranes with a Prosorb sample preparation cartridge (Perkin Elmer:ABI, Foster City, CA). The membranes were covered with a glass fiber disc and moistened with $35 \mu \mathrm{l}$ of $30 \mathrm{mg} / \mathrm{ml}$ $\mathrm{CNBr}$ in $70 \%$ formic acid. The digestion was at room temperature for 12-16 hr. The membrane was dried and placed in the ABI 492 gas phase sequencer (Perkin Elmer:ABI).

The sequences reported herein were from murine OVA-specific transfer factor, murine ferritin-specific transfer factor, and bovine HSV-1 glycoprotein D-specific transfer factor. The molar concentrations of each amino acid at each cycle were used to determine the primary calls.

\section{Synthesis of Peptides}

The peptides LLYAQDLEDN, LLYAQDVEDN, LLYAQDLED, LYAQDLEDN, YAQDLEDN, AQDLEDN, and LAYAQKLEAN were synthesized with an ABI 431A peptide synthesizer (Perkin Elmer: ABI) by the Molecular Resources Laboratory of the National Jewish Medical and Research Center, Denver, CO. Briefly, the products were cleaved with hydrofluoric acid, the mass was determined by matrix-assisted laser desorption/ionization (MALDI) mass spectrometry, purified by HPLC and the mass of the final products was redetermined by MALDI mass spectrometry. In some instances the primary sequence of the synthetic peptides was confirmed by sequencing in a different laboratory.

\section{Inhibition of Transfer Factor Activity with Peptides}

Two protocols were used. In the first experiments LLYAQDLEDN was dissolved in HBSS to give a $2 \times 10^{-4} \mathrm{M}$ solution; $0.5 \mathrm{ml}$ of this was given intraperitoneally (IP) to six BALB/ cByJ female mice 7 hours and, again, $30 \mathrm{~min}$ before the mice received $10^{7}$ lymphocyte equivalents (approx. 0.1 pMol) of affinity-purified transfer factor intraperitoneally. The peptide was again injected on the next day 6 hours and, again, 30 min before the mice were injected in 
the footpads with antigen and diluent. Another injection of peptide solution was given $30 \mathrm{~min}$ before the footpad responses were read.

The majority of the studies of the effects of administration of peptides on expression of delayed-type hypersensitivity by transfer factor recipients were done by administering the peptide at the same time that the transfer factor was given. The dose of transfer factor $\left(10^{7} \mathrm{lym}-\right.$ phocyte equivalents or $0.1 \mathrm{pMol}$ ) was selected, because it produces approximately halfmaximal responses in the quantitative footpad swelling assay (6).

\section{Results}

\section{Amino Acid Sequencing}

Attempts at performing N-terminal amino acid sequencing of intact, purified transfer factor molecules were not successful. It was assumed that the $\mathrm{N}$-terminal amino acid was blocked. It was then decided to attempt sequencing of cleavage fragments of purified transfer factors. Cyanogen bromide was selected, because amino acid composition analyses suggested that each transfer factor molecule contained two methionines (Rozzo and Kirkpatrick, unpublished). Cyanogen bromide fragments from two preparations of equine ferritin-specific transfer factor from murine donors, two preparations of HSV-1 glycoprotein D-specific transfer factor from bovine donors, and three preparations of chicken ovalbumin-specific transfer factor from murine donors were digested and sequenced. The sequences of the apparent conserved regions are shown in Table 1.

The methionine at position -1 can be assumed, because cyanogen bromide cleaves on the carboxy-side of methionine. Our sequencing facility does not make a call from the first cycle of Edman chemistry, so the identity of the amino acid at position 1 is not known. With 1 of the 3 preparations of ovalbumin-transfer factor, the amount of amino acid at position 2 was insufficient to permit identification. However, with other preparations, there was a remarkable consistency of the sequences from position 2 through position 11 and essentially complete agreement at positions 2, 3, 4, 5, 6, 7, 9 and 10 (Table 1). A consensus sequence is MXLLYAQDL/VEDN.

Comparison of the sequences LLYAQDLEDN and LLYAQDVEDN with the GENBANK non-redundant database using the BLASTP 2.0.9 and TBLASTN 2.0.9 programs (National Center for Biotechnology Information [NCBI], Bethesda, MD) did not identify any proteins containing these sequences or nucleic acid sequences that encoded these peptides.

\section{Do the Identified Sequences LLYAQDLEDN and LLYAQDVEDN Have Transfer Factor Activity?}

To test the hypothesis that the peptides LLYAQDLEDN or LLYAQDVEDN were responsible for the immunological activity of transfer factors, mice were given either $10^{7}$ lymphocyte equivalents (approximately $0.1 \mathrm{pMol}$ ) of either ferritin-specific or ovalbumin-specific murine transfer factor or $0.1 \mu \mathrm{Mol}$ of LLYAQDLEDN or

Table 1. Sequences of cyanogen bromide cleavage fragments from purified transfer functions

\begin{tabular}{|c|c|c|c|c|c|c|c|c|c|c|c|c|c|c|c|c|c|}
\hline \multirow{3}{*}{$\begin{array}{l}\text { Transfer Factor } \\
\text { murine ferritin }-1\end{array}$} & \multicolumn{17}{|c|}{ Amino Acid Position } \\
\hline & -1 & $\mathbf{1}$ & & & & 5 & & & & 10 & & & & 15 & & & \\
\hline & $\mathbf{M}$ & $\mathrm{x}$ & $\mathrm{L}$ & $\mathrm{L}$ & $\mathrm{Y}$ & A & Q & $\mathrm{D}$ & $\mathrm{V}$ & $\mathrm{E}$ & $\mathrm{D}$ & $\mathbf{N}$ & I & $\mathbf{N}$ & $\mathrm{D}$ & $\mathrm{E}$ & I \\
\hline murine ferritin -2 & M & $\mathrm{x}$ & $\mathrm{L}$ & $\mathrm{L}$ & $\mathrm{Y}$ & A & Q & $\mathrm{D}$ & V & $\mathrm{E}$ & $\mathrm{D}$ & $\mathbf{N}$ & I & $\mathbf{N}$ & $\mathrm{D}$ & $\mathrm{E}$ & I \\
\hline bovine HSVgD - 1 & M & $\mathbf{x}$ & $\mathrm{L}$ & $\mathrm{L}$ & $\mathrm{Y}$ & A & $\mathrm{Q}$ & $\mathrm{D}$ & $\mathrm{L}$ & $\mathrm{E}$ & $\mathrm{D}$ & $\mathbf{N}$ & $\mathrm{T}$ & $\mathrm{K}$ & $\mathrm{V}$ & $\mathrm{D}$ & $\mathrm{K}$ \\
\hline bovine HSVgD - 2 & M & $\mathbf{x}$ & $\mathrm{L}$ & $\mathrm{L}$ & $\mathrm{Y}$ & A & $\mathrm{Q}$ & $\mathrm{D}$ & $\mathrm{L}$ & $\mathrm{E}$ & $\mathrm{D}$ & $\mathbf{N}$ & $\mathrm{T}$ & $\mathrm{K}$ & $\mathrm{V}$ & $\mathrm{D}$ & $\mathrm{K}$ \\
\hline murine OVA - 1 & M & $\mathbf{x}$ & $\mathrm{L}$ & $\mathrm{L}$ & $\mathrm{x}$ & $\mathbf{x}$ & $\mathrm{Q}$ & $\mathrm{D}$ & $\mathrm{L}$ & $\mathrm{E}$ & $\mathrm{D}$ & $\mathbf{N}$ & $\mathrm{T}$ & $\mathrm{T}$ & $\mathrm{D}$ & K & \\
\hline murine OVA -2 & M & $\mathrm{x}$ & $\mathrm{L}$ & $\mathrm{L}$ & $\mathrm{Y}$ & A & $\mathrm{Q}$ & $\mathrm{D}$ & L & $\mathrm{E}$ & $\mathrm{D}$ & I & $\mathrm{E}$ & A & K & & \\
\hline murine OVA -3 & M & $\mathbf{x}$ & $\mathrm{x}$ & $\mathrm{L}$ & $\mathrm{Y}$ & A & Q & $\mathrm{D}$ & $\mathrm{V}$ & $\mathrm{E}$ & $\mathrm{D}$ & $\mathbf{N}$ & $\mathrm{E}$ & $\mathrm{A}$ & $\mathrm{D}$ & & \\
\hline consensus sequence & $\mathbf{M}$ & $\mathbf{x}$ & $\mathrm{L}$ & L & $\mathrm{Y}$ & A & $\mathrm{Q}$ & $\mathrm{D}$ & $\mathrm{L} / \mathrm{V}$ & $\mathrm{E}$ & $\mathrm{D}$ & $\mathbf{N}$ & & & & & \\
\hline
\end{tabular}

$\mathrm{x}$, unidentified amino acid 
LLYAQDVEDN intraperitoneally. Twenty-four hours later the recipients were footpad-tested for delayed hypersensitivity to ferritin or ovalbumin. As shown in Figure 1, there were significant footpad responses to ferritin in the recipients of the ferritin transfer factor $(p<$ 0.001 ) and to OVA in the recipients of the OVA transfer factor $(p<0.001)$. The recipients of the peptide, LLYAQDLEDN, did not express delayed-type hypersensitivity to either ferritin or ovalbumin. The footpad swelling responses by these mice were not significantly greater than the responses to Hank's balanced salt solution, which produces swellings of $2-4 \times 10^{-2} \mathrm{~mm}$. Injection of the solutions of ferritin or ovalbumin into the footpads of control mice produced swellings of $1-5 \times 10^{-2} \mathrm{~mm}$. In addition, recipients of LLYAQDVEDN did not express delayed hypersensitivity to ferritin or OVA (data not shown).
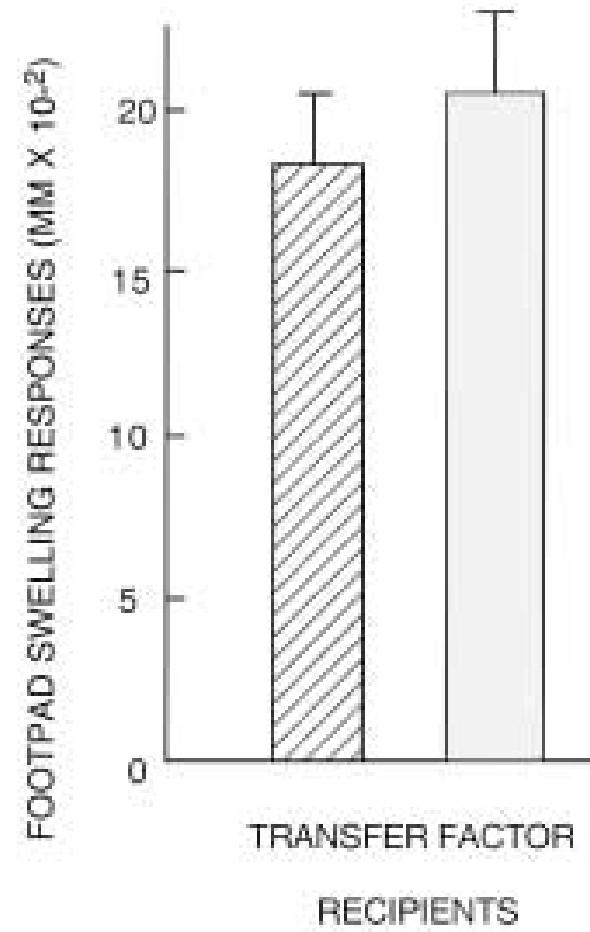

Fig. 1. Does the peptide LLYAQDLEDN have transfer factor activity? Groups of mice were given either ferritin-specific or ovalbumin-specific murine transfer factors (TF) or LLYAQDLEDN. Footpad testing with ferritin and ovalbumin was done $24 \mathrm{hr}$ later and the responses were read after $18 \mathrm{hr}$. Untreated control mice developed footpad swelling responses to Hanks Balanced Salt Solution (HBSS) of $2-4 \times 10^{-2} \mathrm{~mm}$. In contrast, the transfer factor recipients developed large responses
Does Administration of LLYAQDLEDN Alter Expression of Delayed-type Hypersensitivity by Recipients of Transfer Factors?

Two protocols were evaluated. In one, mice received multiple doses of LLYAQDLEDN prior to receiving the transfer factor. In the second, either LLYAQDLEDN or LLYAQDVEDN was given at the same time as the transfer factor. The footpad tests were started $24 \mathrm{hr}$ after intraperitoneal administration of the transfer factor with or without the peptide; the footpad swelling responses were measured $18 \mathrm{hr}$ later. Identical results were obtained with both protocols.

As shown in Figure 2, treatment with LLYAQDLEDN completely "blocked" expression of delayed-type hypersensitivity to ferritin by recipients of ferritin-specific transfer factor and to ovalbumin by recipients of ovalbuminspecific transfer factor. The same results were
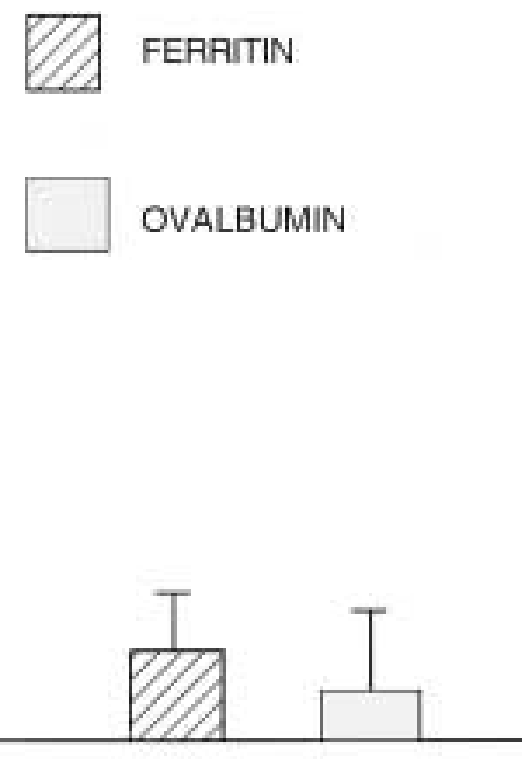

LLYAODLEDN RECIPIENTS

to the corresponding antigen. Ferritin transfer factor recipients had responses of $18.50 \pm 1.75 \times 10^{-2}$ $\mathrm{mm}$ to ferritin and OVA transfer factor recipients had responses of $20.50 \pm 2.50 \times 10^{-2} \mathrm{~mm}$ responses to ovalbumin. In both groups the responses were significantly $(p<0.001)$ greater than the controls. There were no footpad swelling responses to OVA or ferritin by recipients of LLYAQDLEDN. 


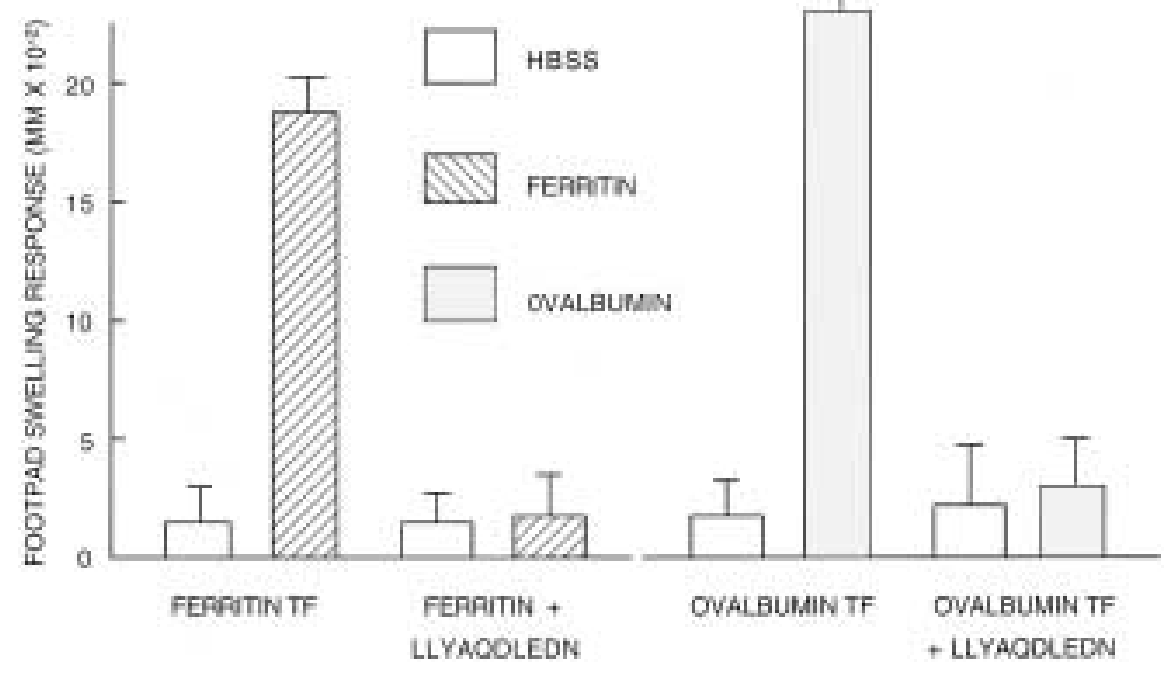

Fig. 2. Inhibition of expression of delayedtype hypersensitivity by recipients of transfer factor (TF) by administration of LLYAQDLEDN. Groups of mice were given either ferritin-specific or ovalbumin-specific transfer factors (approximately $0.1 \mathrm{pMol}$ ) of murine origin. Other mice received the same doses of the transfer factors and $0.1 \mu \mathrm{M}$ of LLYAQDLEDN. Footpad testing was

obtained in two additional experiments with ovalbumin transfer factor and a second experiment with ferritin-specific transfer factor. As shown in Figure 3, administration of LLYAQDLEDN also inhibited expression of delayedtype hypersensitivity to Herpes simplex by recipients of Herpes simplex glycoprotein D-specific transfer factor. LLYAQDLEDN inhibited expression of delayed-type hypersensitivity to HSV-gD by mice that received HSVtransfer factor of either murine or bovine origin (Fig. 3). Thus, the homologous sequences that were described in Table 1 were relevant to the inhibition of immunological activities of transfer factors from different species.

What is the Minimal Peptide That Has Inhibitory Activity?

A series of peptides that were related to LLYAQDLEDN were synthesized and tested for their ability to interfere with expression of delayed-type hypersensitivity in transfer factor-treated recipients. HSVgD-specific, ferritinspecific and ovalbumin-specific transfer factors were studied. These experiments are summarized in Table 2, in which LLYAQDLEDN was assigned a value of $100 \%$ inhibitory activity. Removal of the carboxy-terminal asparagine or the amino-terminal leucine essentially ablated done after $24 \mathrm{hr}$ and the responses were read $18 \mathrm{hr}$ later. The responses to the antigens by the transfer factor recipients were significantly greater than the responses to HBSS ( $p<0.001$ in both studies). Note that concomitant administration of LLYAQDLEDN essentially ablated expression of delayedtype hypersensitivity.

the inhibitory activity. However, when the peptide LYAQDLEDN was studied in a 10-fold greater concentration, significant inhibitory activity was observed $(0.05>p>0.02)$. The peptide LLYAQDVEDN, which was also obtained in the sequencing experiments (Table 1), had approximately $1 \%$ of the inhibitory activity of LLYAQDLEDN. The inhibitory activity of $10^{-6} \mathrm{M}$ LLYAQDLEDN was not significantly different from that of $10^{-4} \mathrm{M}$ LLYAQDVEDN $(p>0.20)$. A randomly substituted peptide, LAYAQKLEAN, was not inhibitory.

Does LLYAQDLEDN Inhibit Expression of Delayedtype Hypersensitivity by Actively Sensitized Mice?

These experiments were done to test the hypothesis that LLYAQDLEDN was immunosuppressive. Mice were immunized with ferritin in FCA or infected with sublethal doses of virulent human Herpes simplex virus. After 3 weeks, groups of mice were footpad-tested with either ferritin or irradiated HSV-1. A subgroup of mice in each group received $0.5 \mathrm{cc}$ of $2 \times 10^{-4} \mathrm{M}$ LLYAQDLEDN intraperitoneally, $60 \mathrm{~min}$ prior to footpad-testing. As shown in Figure 4, there was no inhibition of expression of delayed-type hypersensitivity by the peptidetreated mice. 


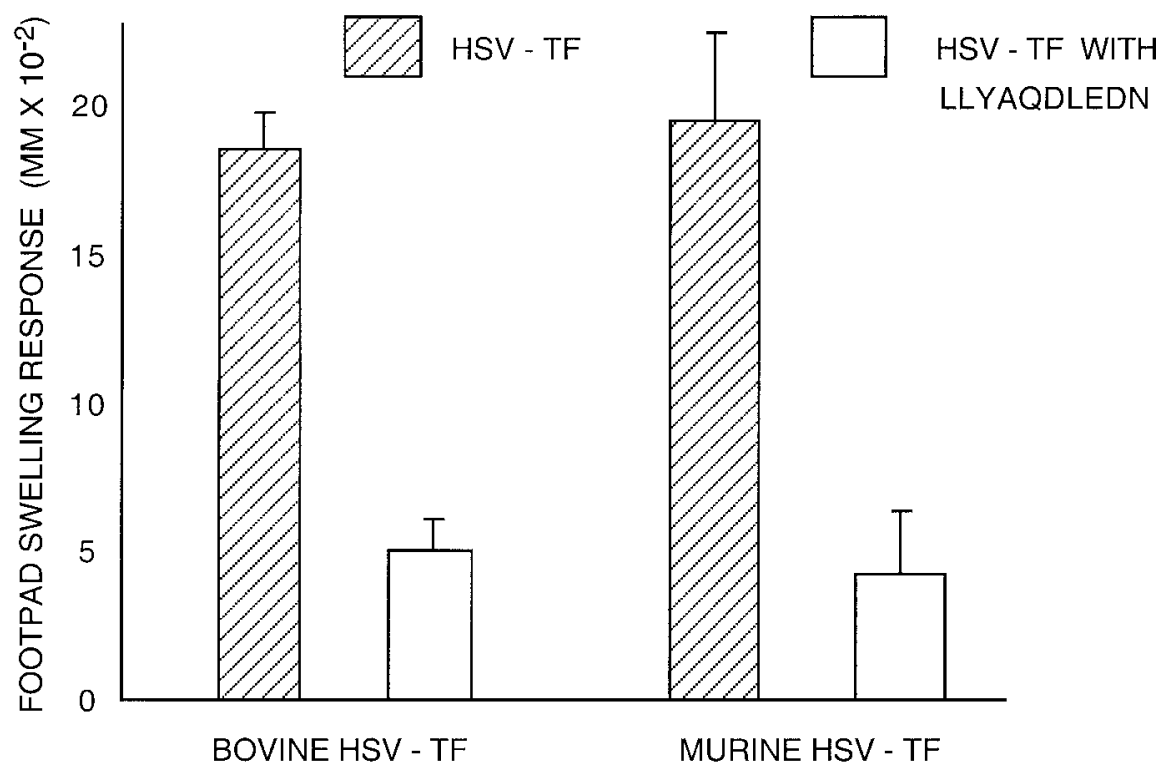

Fig. 3. Inhibition of expression of delayedtype hypersensitivity to Herpes simplex by LLYAQDLEDN. Herpes simplex-glycoprotein Dspecific transfer factors of either murine or bovine origin were given to BALB/cByJ mice (approximately 0.1 pMol per mouse). Other groups of mice received the same doses of the transfer factors and $0.1 \mu \mathrm{M}$ of LLYAQDLEDN. Footpad testing was done as described. Significant $(p<0.001)$ footpad responses were observed in the transfer factor re-

\section{Discussion}

Transfer of delayed-type hypersensitivity with cell lysates was first described by Lawrence in the mid-1950's (9). This observation was made in humans and was in conflict with previous studies in guinea pigs showing that transfer of delayed-type hypersensitivity required syngeneic, intact living cells (10). The mechanisms of action and the complete structures of transfer factors have yet to be determined. A variety of molecular models have been offered, but none have been proved. There have been concerns about how specific immunologic information could be transferred by molecules with molecular weights $\leq 10,000$ Da (11). Our studies of the structures of transfer factors are intended to address these questions.

To a degree, much of the continuing research on transfer factors has been driven by clinical observations. In 1970, Levin and coworkers (12) reported that administration of a leukocyte dialysate that contained transfer factors improved cell-mediated immune responses and provided clinical benefits to a patient with the Wiskott-Aldrich syndrome, an

cipients. The recipients of both transfer factor and LLYAQDLEDN had footpad responses that were not different from the responses to HBSS. For the recipients of bovine Herpes simplex virus transfer factor (HSV-TF) the response to HBSS was $6.33 \pm$ $1.52 \times 10^{-2} \mathrm{~mm}$ and the response to HSV was $5.17 \pm 0.83 \times 10^{-2} \mathrm{~mm}(p>0.50)$; the recipients of murine HSV-TF had responses to HBSS of 2.00 $\pm 1.33 \times 10^{-2} \mathrm{~mm}$ and to HSV of $4.25 \pm 2.13 \times$ $10^{-2} \mathrm{~mm}(p>0.30)$.

X-linked immunodeficiency disease. Similar immunologic and clinical benefits have been observed in patients with chronic mucocuta-

Table 2. Inhibition of transfer factor activity by synthetic peptides

\begin{tabular}{lc}
\hline Sequence & $\begin{array}{c}\text { Relative Inhibitory } \\
\text { Activity }\end{array}$ \\
\hline LLYAQDLEDN $\left(10^{-4} \mathrm{M}\right)$ & $100 \%$ \\
LLYAQDLED $\left(10^{-4} \mathrm{M}\right)$ & 8 \\
LYAQDLEDN $\left(10^{-4} \mathrm{M}\right)$ & 0 \\
LYAQDLEDN $\left(10^{-3} \mathrm{M}\right)$ & 42 \\
YAQDLEDN $\left(10^{-4} \mathrm{M}\right)$ & 13 \\
LLAYQDVEDN $\left(10^{-4} \mathrm{M}\right)$ & 66 \\
LLYAQDLEDN $\left(10^{-6} \mathrm{M}\right)$ & 57 \\
LAYAQKLEAN $\left(10^{-4} \mathrm{M}\right)$ & 9 \\
\hline
\end{tabular}

Each mouse received $1.0 \mathrm{ml}$ of a solution containing the stated concentration of peptide. Note that when the concentration of LYAQDLEDN was increased 10-fold, significant $(0.05>p>0.02)$ inhibition of the activity of the transfer factor was seen. The inhibitory activity of $10^{-4} \mathrm{M}$ LLYAQDVEDN was not significantly different from that of $10^{-6}$ M LLYAQDLEDN $(p>0.20)$. 

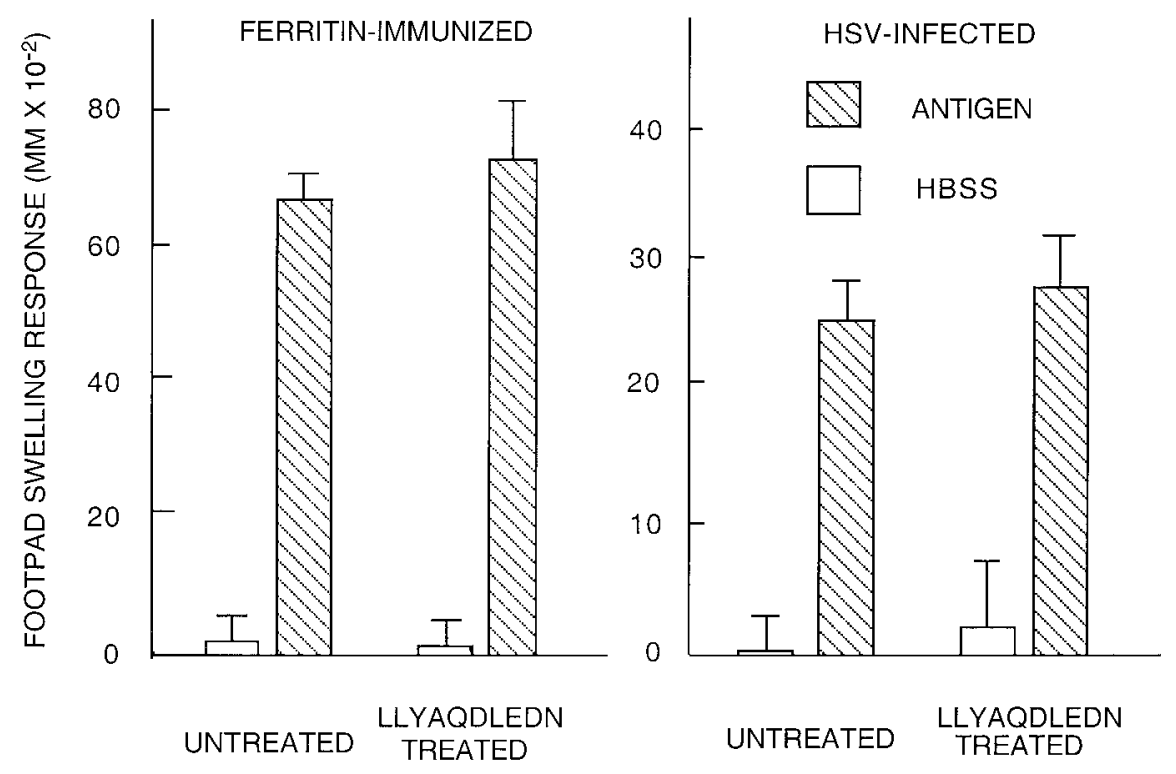

Fig. 4. Effect of LLYAQDLEDN on expression of delayed-type hypersensitivity by immunized mice. Mice were sensitized to ferritin by immunization with ferritin in Freund's complete adjuvant (FCA) and to Herpes simplex virus (HSV) by infection with sublethal doses of virulent human HSV-1. Treatment with LLYAQDLEDN did not inhibit expression of delayed-type hypersensitivity (DTH) in either group. For ferritin-immune mice

neous candidiasis, a disorder with impaired cytokine production $(13,14)$. Other clinical trials have shown that treatment with specific transfer factor-containing dialysates can prevent relapses in patients with recurrent Herpes simplex infections $(15,16)$, and provide a means for treating intestinal cryptosporidiosis in patients with acquired immune deficiency syndrome (AIDS) (17). The observation that treatment of children with acute leukemia with a varicella zoster-specific transfer factor could prevent chickenpox raised the possibility that transfer factors could provide a means for prophylaxis of diseases for which cell-mediated immunity is essential (18).

Little is known about the mechanisms of the effects of transfer factors on immune responses. Clinical trials have demonstrated the close concordance between induction of antigen-specific delayed-type hypersensitivity and beneficial clinical outcomes (12-14). Recent studies in murine recipients have shown that in vivo administration of transfer factors endows the recipients' spleen cells with the property of responding to the corresponding antigen in vitro by secreting $\gamma$-interferon (19). Production of interleukin (IL)-2, IL-4 and IL-

the footpad response was $68.17 \pm 11.66 \times 10^{-2}$ $\mathrm{mm}$; for ferritin-immune, LLYAQDLEDN-treated mice, footpad response was $75.00 \pm 7.76 \times 10^{-2}$ $\mathrm{mm}(p>0.60)$. Mice that were sensitized to HSV by sublethal infection developed footpad responses to irradiated HSV of $24.80 \pm 3.17 \times 10^{-2} \mathrm{~mm}$. The identically infected, LLYAQDLEDN-treated mice had footpad responses of $27.80 \pm 3.98 \times 10^{-2} \mathrm{~mm}$ $(\mathrm{p}>0.50)$.

10 was also measured and was not affected by the treatment.

Our laboratory focused on methods for isolation of specific transfer factors from the leukocyte dialysates and determination of the structures of transfer factors. A simple and reproducible purification process has been developed (6) and this report describes the sequences of what is believed to be a conserved portion of molecules with transfer factor activity. Searches of the available databases using the NCBI website did not reveal other proteins with the sequences LLYAQDLEDN or LLYAQDVEDN or known DNA sequences that encoded these peptides. The sequence LEDN was found in positions 136-139 of the recently reported pancreatic protein apolipoprotein L (20). The sequences LLYAQDLEDN and LLYAQDVEDN were not found in the primary structures of ferritin, ovalbumin or Herpes simplex glycoprotein $\mathrm{D}$. This provides direct evidence against the proposal that transfer factors are "highly immunogenic" fragments of antigens.

We were not surprised that the apparently conserved peptides did not transfer the ability to express delayed-type hypersensitivity to re- 
cipients. Our current model for the functional structure of transfer factors describes a conserved or constant region that serves as a binding site for cells that are the primary targets of transfer factors. Different regions of transfer factor molecules are hypothesized to have variable amino acid sequences that determine the epitope specificity of individual transfer factors.

The peptides that have been identified in this research should be valuable for future studies. First, appropriately labeled peptides should be useful for identification of the putative target cells or molecules for transfer factors. Such experiments are in progress in our laboratory. Second, cDNAs that are complementary to the peptides may serve as probes for identification and isolation of genes for specific transfer factors.

The relationship of transfer factors to other antigen-binding molecules deserves comment. The small molecular weights of transfer factors (molecular mass $\cong 5000 \mathrm{Da}$ ) (6) are quite different from immunoglobulins, major histocompatibility complex molecules and T-lymphocyte receptors. Like immunoglobulins, transfer factors bind to intact antigen molecules (8), but reduction and alkylation of transfer factors does not dissociate them into heavy chains and light chains (Kirkpatrick and Rozzo unpublished). T-lymphocyte receptors do not bind intact antigen molecules as transfer factors do, yet the immune responses that are "transferred" to recipients of transfer factors are mediated by $\mathrm{T}$ lymphocytes. It is possible that transfer factors operate through an unique mechanism of antigen presentation and T-cell activation.

The position of the peptides, LLYAQDLEDN and LLYAQDVEDN in the complete sequence of transfer factors is unknown, but additional sequencing should clarify this matter. We considered the possibility that the peptides were "copurifying" molecules. The fact that they are not detected, unless the purified intact transfer factors are cleaved with cyanogen bromide, and the finding that the peptides interfere with expression of the immunological activities of transfer factors in vivo makes this unlikely. The marked differences in inhibitory activity of LLYAQDLEDN and LLYAQDVEDN are striking. Molecules with both sequences have transfer factor activity. It will be important to know if the two peptides, which may represent a single base substitution $(C \rightarrow G$ or $U \rightarrow G)$, are related to different affinities of transfer factors for their "target" cells.
It was important to note that administration of LLYAQDLEDN did not affect expression of delayed-type hypersensitivity by recipients that were sensitized either by sublethal infection with HSV-1 or by immunization with ferritin. This is a fascinating observation that may indicate some fundamental difference between the mechanisms of active immunization and transfer factors. On the other hand, it may be the result of the treatment dosage or schedule. The experiments with LYAQDLEDN indicate that there is a dose-response relationship for the suppression of expression of delayed-type hypersensitivity by this peptide (Table 2 ) and dose-response relationships for transfer factors have been reported as well $(6,21)$. Nonetheless, our observation indicates that transfer factors can be used to reconstitute cellular immunodeficiency in clinical settings without affecting the recipient's ability to develop protective immune responses after infections or immunizations.

\section{Acknowledgments}

This research was supported by a Research Agreement with EntreMed, Inc., Rockville, MD. The cyanogen bromide fragments were prepared by Dr. Martin McDermott, Boulder, CO. The sequencing was done by Mr. Shad Ewbanks of the National Jewish Medical and Research Center, Denver, CO. The recombinant Herpes simplex glycoprotein D was provided by Drs. Gary Cohen and Roselyn Eisenberg, University of Pennsylvania School of Dentistry, Philadelphia, PA. Discussions of the data with Dr. John Freed of the National Jewish Medical and Research Center, Denver, CO., the critiques of the manuscript by Dr. Matt Jonsen and the technical assistance of Mr. Kevin O'Brien of Cytokine Sciences, Inc, Denver, CO are greatly appreciated.

\section{References}

1. Lawrence HS. (1974) Transfer factor in cellular immunity. The Harvey Lectures, Series 68: 239-350.

2. Burger DR, Vandenbark AA, Finke P, Vetto RM. (1977) De novo appearance of KLH transfer factor following immunization. Cell Immunol. 29: 410-413.

3. Petersen EA, Greenberg LE, Manzara T, Kirkpatrick CH. (1981) Murine transfer factor. I. De- 
scription of the model and evidence for specificity. J. Immunol. 126: 2480-2484.

4. Kirkpatrick CH, Rozzo SJ, Mascali JJ, Merryman CF. (1985) Murine transfer factor. II. Transfer of delayed hypersensitivity to synthetic antigens. J. Immunol. 134: 1723-1727.

5. Borkowsky W, Lawrence HS. (1981) Deletion of antigen-specific activity from leukocyte dialysates containing transfer factor by antigencoated polystyrene. J. Immunol. 126: 486-489.

6. Rozzo SJ, Kirkpatrick CH. (1992) Purification of transfer factors. Molec. Immunol. 29: 167-182.

7. Sisk WP, Bradley JD, Leipold RJ, et al. (1994) High-level expression and purification of secreted forms of herpes simplex virus type 1 glycoprotein D synthesized by baculovirus-infected insect cells. J. Virol. 68: 766-775.

8. Kirkpatrick CH, Rozzo SJ, Mascali JJ. (1985) Murine transfer factor. III. Specific interactions between transfer factor and antigen. J. Immunol. 135: 4027-4033.

9. Lawrence HS. (1955) The transfer in humans of delayed hypersensitivity to streptococcal M substance and to tuberculin with disrupted leukocytes. J. Clin. Invest. 34: 219-232.

10. Chase MW. (1945) The cellular transfer of cutaneous hypersensitivity to tuberculin. Proc. Soc. Exp. Biol. Med. 59: 134-136.

11. Bloom BR. (1980) Does transfer factor act specifically or as an immunologic adjuvant? N. Engl. J. Med. 288: 908-909.

12. Levin AS, Spitler LE, Stites DP, Fudenberg HH. (1970) Wiskott-Aldrich syndrome, a genetically determined cellular immunologic deficiency: clinical and laboratory responses to therapy with transfer factor. Proc. Natl. Acad. Sci. U.S.A. 67: 821-828.

13. Kirkpatrick, CH, Chandler JW, Schimke RN.
(1970) Chronic mucocutaneous moniliasis with impaired delayed hypersensitivity. Clin. Exp. Immunol. 6: 375-385.

14. Kirkpatrick CH, Greenberg LE. (1979) Treatment of chronic mucocutaneous candidiasis with transfer factor. In: Khan A, Kirkpatrick $\mathrm{CH}$, Hill NO (eds.) Immune Regulators In Transfer Factor. Academic Press, New York, pp. 547-559.

15. Dwyer JM. (1983) The use of antigen specific transfer factor in the management of infections with herpes viruses. In: Kirkpatrick $\mathrm{CH}$, Burger DR, Lawrence HS (eds.). Immunobiology of Transfer Factor. Academic Press, New York, pp. 233-243.

16. Pizza G, Visa D, DeVinci C, et al. (1996) Orally administered HSV-specific transfer factor (TF) prevents genital or labial herpes relapses. Biotherapy 9: 67-72.

17. McMeeking A, Borkowsky W, Klesius PH, Bonk S, Holzman RS, Lawrence HS. (1990) A controlled trial of bovine dialyzable leukocyte extract for cryptosporidiosis in patients with AIDS. J. Infect. Dis. 161: 108-112.

18. Steele RW, Myers MG, Vincent MM. (1980) Transfer factor for the prevention of varicellazoster infection in childhood leukemia. N. Engl. J. Med. 303: 355-359.

19. Alvarez-Thull L, Kirkpatrick CH. (1996) Profiles of cytokine production in recipients of transfer factors. Biotherapy 9: 55-59.

20. Duchateau PN, Pullinger CR, Orellama RE, et al. (1997) Apolipoprotein L, a new human high density lipoprotein apolipoprotein expressed by the pancreas. J. Biol. Chem. 272: 25576-25582.

21. Rozzo SJ, Merryman CF, Kirkpatrick CH. (1988) Murine transfer factor. IV. Studies with genetically regulated immune responses. Cell Immunol. 115: 130-145. 